\title{
Os avanços da odontologia minimamente invasiva nos dias atuais
}

\author{
The advances of minimally invasive dentistry in current days \\ Los avances de la odontología mínimamente invasiva en los días actuales
}

José Milton de Aquino e Silva Neto ${ }^{1 *}$, Ludimila Azevedo Costa Agra ${ }^{1}$, Mariana Cavalcanti Marques Luz $^{1}$, Sysllânia Vitória Pôrto Souza ${ }^{1}$, Jhulliana Vitorio dos Santos ${ }^{1}$, Izabel Cristina Gomes de Mendonça ${ }^{1}$.

\section{RESUMO}

Objetivo: Efetuar uma revisão narrativa sobre os recursos terapêuticos para tratamento das lesões dentárias, provocadas pelas cáries, empregando técnicas minimamente invasivas. Revisão bibliográfica: Nos dias atuais a utilização de técnicas que visam as condutas de mínima invasão, nos inúmeros âmbitos que envolvem a área da saúde, vem progredindo constantemente. Quando se relaciona as técnicas utilizadas de maneira minimamente invasiva pelos Cirurgiões Dentistas constata-se que essas condutas vêm progredindo gradualmente, procurando em todo o tempo levar em consideração os processos biológicos inerentes aos tecidos que envolvem os dentes, implicando, dessa forma, na constatação de que os materiais utilizados para a restauração possuem características biológicas inferiores aos tecidos naturais presentes nos elementos dentários. Com o aperfeiçoamento das técnicas e materiais adesivos, observou-se uma postura diferenciada dos profissionais, principalmente os mais jovens, que desenvolveram uma mentalidade mais consciente quanto à manutenção destas estruturas no decorrer das técnicas restauradoras. Considerações finais: A Odontologia Minimamente Invasiva tem demostrado efetividade nos tratamentos estabelecidos, deixando claro que o melhoramento dos materiais restauradores, que possuem atribuições para agirem com características adesivas, é de bastante relevância na forma da conduta clínica estabelecida pelo profissional.

Palavras-chave: Materiais dentários, Tratamento conservador, Cárie dentária.

\begin{abstract}
Objective: To carry out a narrative review on the therapeutic resources for the treatment of dental injuries, caused by cavities, using minimally invasive techniques. Literature review: Nowadays, the use of techniques that aim at the minimum invasion practices, in the innumerable areas that involve the health area, has been progressing steadily. When the techniques used in a minimally invasive manner by Dental Surgeons are listed, it appears that these behaviors have been progressing gradually, seeking at all times to take into account the biological processes inherent in the tissues surrounding the teeth, thus implying in the finding of that the materials used for the restoration have biological characteristics inferior to the natural tissues present in the dental elements. With the improvement of adhesive techniques and materials, a different posture of professionals was observed, especially the younger ones, who developed a more conscious mentality regarding the maintenance of these structures during the course of restorative techniques. Final considerations: Minimally Invasive Dentistry has shown effectiveness in the established treatments, making it clear that the improvement of restorative materials, which have attributions to act with adhesive characteristics, is of great relevance in the form of clinical conduct established by the professional.
\end{abstract}

Keywords: Dental materials, Conservative treatment, Dental caries.

\section{RESUMEN}

Objetivo: Realizar una revisión narrativa sobre los recursos terapéuticos para el tratamiento de las lesiones dentales, provocadas por caries, mediante técnicas mínimamente invasivas. Revisión bibliográfica: En la actualidad, el uso de técnicas que apuntan a las prácticas de mínima invasión, en las innumerables áreas que involucran al área de salud, ha ido progresando de manera constante. Cuando se enumeran las técnicas empleadas de forma mínimamente invasiva por los Cirujanos Dentales, parece que estos comportamientos han ido progresando de forma paulatina, intentando en todo momento tener en cuenta los procesos biológicos

${ }^{1}$ Centro Universitário CESMAC (CESMAC), Maceió - AL. `E-mail: milton_neto_166@hotmail.com 
inherentes a los tejidos que envuelven los dientes, implicando así en el hallazgo de que los materiales utilizados para la restauración tienen características biológicas inferiores a los tejidos naturales presentes en los elementos dentales. Con la mejora de las técnicas y materiales adhesivos, se observó una postura diferente de los profesionales, especialmente los más jóvenes, quienes desarrollaron una mentalidad más consciente respecto al mantenimiento de estas estructuras durante el transcurso de las técnicas restauradoras. Consideraciones finales: La Odontología Mínimamente Invasiva ha demostrado eficacia en los tratamientos establecidos, dejando claro que la mejora de los materiales restauradores, que tienen atribuciones para actuar con características adhesivas, es de gran relevancia en la forma de la conducta clínica establecida por el profesional.

Palabras clave: Materiales dentales, Tratamiento conservador, Caries dental.

\section{INTRODUÇÃO}

Nas últimas décadas as pesquisas na área odontológica vêm avançando cada vez mais, buscando sempre evoluir nas técnicas empregadas, analisando cada procedimento de maneira particularizada e promovendo modificações das condutas clínicas implantadas ao longo dos anos. É nítido a indicação do estabelecimento das técnicas de interpelações de formas mais conservadoras, no que se refere à conservação das estruturas dentárias, buscando sempre respeitar as características biológicas de cada um dos tecidos que compõem o órgão dental, e dispondo de recursos que mantenham ao máximo a vitalidade do dente, deixando a exodontia como a última opção de tratamento (SANTOS ML, 2017).

Observa-se que ao longo de muitos anos, existia uma padronização quanto à abordagem terapêutica utilizada para fazer o tratamento de elementos dentais cariados, que preconizava a completa remoção dos tecidos cariados seguida do restabelecimento da forma e função do dente pela restauração (KAYA MS, et al., 2018). A preparação cavitária era extensa, feita de maneira geométrica predeterminada, levando em consideração as características e propriedades dos materiais restauradores em detrimento da preservação dos tecidos biológicos, o que levava a uma degradação desnecessária das estruturas hígidas, reduzindo assim a resistência do elemento dentário às forças mastigatórias que incidem sobre a restauração (EL-SAFTY S, et al., 2012).

Atualmente o Cirurgião Dentista (CD) busca estabelecer a preservação das partes que compõe as estruturas dos elementos dentários, mudança de atitude implementada em decorrência dos achados das pesquisas científicas realizadas, principalmente na área de cariologia e materiais odontológicos, tendo por consequência resultados mais satisfatórios e representativos. Um dos fatores em especial que fez com que houvesse esse avanço benéfico foi o reconhecimento de como ocorria a evolução da cárie, assim como o melhoramento dos materiais restauradores adesivos contendo flúor, que possibilitou a elaboração de planejamentos cavitários mais conservadores, tornando-se viável a implantação de uma Odontologia Minimamente Invasiva (OMI) (FRANÇA, S, 2016).

De acordo com Massara MLA, et al. (2012) e Meyer-Lueckel H. et al. (2016) as intervenções para remoção da dentina que se encontra cariada vem sendo grandemente debatidas a partir da difusão de pesquisas cientificas que expõem a capacidade de reação do complexo dentina polpa à invasão bacteriana, bem como a paralização das lesões já estabelecidas provocadas pela cárie na dentina depois de ocorrer o selamento da mesma com diferentes materiais adesivos.

Fundamentando-se na concepção estabelecida através da OMI, a cárie é classificada como sendo uma patologia de origem bacteriana, dispondo como um dos agentes causadores o açúcar, dos quais resultam em lesões das estruturas dos tecidos duros presentes nos elementos dentais, resultante dos ácidos oriundos do processo metabólico das bactérias. O processo carioso inicia-se com uma disfunção do balanço mineral (remineralização/desmineralização) na superfície dentária (MEYER-LUECKEL H, et al., 2016).

Suas causas são decorrentes dos produtos ácidos resultantes dos processos metabólicos bacterianos na degradação de açúcares. Com o fechamento da cavidade cariada, as bactérias, que lá se encontram isoladas do meio bucal não conseguem obter os substratos essenciais para a sua continuidade, ocasionando em aminguamento do número dos microrganismos ou até mesmo seu desaparecimento, paralisando, dessa forma, a evolução da cárie (VALENTIM VCB, et al., 2017). 
O conhecimento acumulado nos últimos anos na área ligada à cariologia, em particular à associação do processo de desencadeamento, evolução e interrupção da lesão cariosa com o progresso e aperfeiçoamento de materiais restauradores que apresentam particularidades de maneiras adesivas e preventivas, como liberação de flúor, estabeleceram a implementação de modificações de suma importância que revolucionaram definitivamente as abordagens da Dentística Operatória e Restauradora, no que se refere ao tratamento da cárie (FEJERSKOV O, et al., 2017; VALENTIM VCB, et al., 2017).

À vista do que foi mencionado, o presente estudo busca efetuar uma revisão narrativa sobre os recursos terapêuticos atuais referentes ao tratamento e agravamento das lesões dentárias, provocadas pelas cáries em dentina, através da adoção de metodologias que visam a conservação das estruturas e da vitalidade do dente durante a intervenção restauradora, destacando a paralisação do avanço carioso com a remoção seletiva de tecido cariado e evidenciando os materiais empregados no selamento das cavidades.

\section{REVISÃO BIBLIOGRÁFICA}

\section{Odontologia Minimamente Invasiva}

O conceito de OMI está respaldado na conservação do máximo possível das disposições estruturais dos elementos dentais sadios e na sobreposição de uma conduta de trabalho que visa transformar o modelo padronizado de processos terapêuticos ultrapassados em uma estratégia de priorização de abordagens biológicas, onde a vitalidade do dente é priorizada, em comunhão com a valorização da promoção de saúde, visando o bem estar do paciente como um todo (FEJERSKOV O e KIDD E, 2011; ZUCCHELLI G, et al., 2013).

Com essas mudanças de condutas, as escolhas feitas de maneira conservadora são levadas em consideração antes do profissional pensar em fazer indicações de metodologias mais agressivas, profundas e mais caras. É importante salientar que, mesmo com toda a evolução tecnológica presente nos dias de hoje, não existe nenhum material restaurador no mercado que se comporte de maneira eficaz e que se iguale ou substitua as estruturas dentárias, além do fato de que qualquer procedimento restaurador envelhece e seus aspectos físicos e químicos se deterioram ao longo dos anos, necessitando de reparos ou substituições as quais tendem a diminuir consideravelmente a permanência do dente na cavidade oral (RUNGCHARASSAENG K, et al., 2012).

De modo geral, em todas especialidades da área odontológica vêm sendo adotados procedimentos que podem ser feitos pelos CDs de maneiras menos invasivas, podendo ser citados na Dentística como exemplos: o processo de remineralização do elemento dental (com flúor, higiene dental e controle da dieta cariogênica), bem como o cuidado através do monitoramento periódico de lesões paralisadas que não foram cavitadas, e o estabelecimento de um modelo cirúrgico-restaurador minimalista que priorize técnicas conservadoras (RUNGCHARASSAENG K, et al., 2012).

Observa-se que o Tratamento Restaurador Atraumático (ART) foi assimilado como sendo uma reinterpretação dos processos de abertura gradual dos tecidos dentais e do capeamento pulpar indireto que visa estabelecer um tratamento conservador realizado na tentativa de manutenção da integridade e vitalidade pulpar (WALSH LJ e BROSTEK AM, 2013).

Nesse enquadramento, a técnica do ART, que preconiza a remoção do tecido dentário amolecido e permanentemente lesado, seguido do selamento com ionômero de vidro, é largamente recomendada na odontopediatria como opção de tratamento conservador em lesões de cárie ativa profundas. A indicação dessa técnica em crianças deve-se principalmente ao fato de dispensar o uso de anestésicos, já que se utiliza unicamente instrumentos manuais durante todas as etapas do preparo cavitário. Na odontopediatria o ART é considerado como um tratamento definitivo, promovido com a intenção de estacionar a evolução da cárie, ao mesmo tempo em que permite uma rápida reação do órgão dental com formação de dentina reacional, impedindo a invasão bacteriana na polpa. É muito bem aceito pelas crianças por ser indolor e necessitar de apenas uma sessão no consultório, além de ser considerada uma maneira moderna e ousada de tratamento na época em que surgiu, atualmente é tida como integrante das abordagens que priorizam a saúde pulpar dentro da filosofia de mínima intervenção, sendo especialmente útil no trato com pacientes especiais por ser essencialmente atraumático (MASSARA MLA, et al., 2012). 


\section{Importância da escolha dos materiais seladores na abordagem minimamente invasiva}

Os materiais que exibem características restauradoras adesivas apresentam bastante relevância na abordagem de tratamento minimamente invasivo, por exemplo: as resinas compostas acompanhadas de sistemas adesivos modernos, que promovem uma melhora na capacidade de adesão com consequente redução da microinfiltração marginal em dentina, os cimentos ionômeros de vidro convencionais, que liberam gradativamente flúor diminuindo a incidência de cárie secundária, e os ionômeros de vidros modificados por resina, mais fáceis de usar e com melhores propriedades mecânicas (MEYER-LUECKEL H, et al., 2016).

No entanto, segundo França S (2016), o decorrer de um processo restaurador que envolve a resina composta necessita de cuidados no controle da umidade durante a sua inserção na cavidade; é preciso levar em consideração também o tipo de sistema adesivo que será empregado, e observar atentamente a técnica de aplicação de ambos, resina e adesivo, responsável por grande parte da eficácia da adesão desse material.

Nos achados dos trabalhos realizados pelos autores Massara MLA, et al. (2012) e Meyer-Lueckel H, et al. (2016), é destacado que os cimentos de ionômero de vidro na atualidade são materiais que apresentam uma boa versatilidade. Existem princípios ativos específicos nos cimentos de ionômero de vidro que fazem com que eles apresentem uma boa compatibilidade com os elementos dentais, sua adesão química é satisfatória além de dispor de liberação de íons flúor, tornando-os assim materiais de primeira escolha, principalmente quando é ressaltado a importância de processos terapêuticos preventivos, em especial nos pacientes que apresentam uma prevalência muito grande de cárie ativa.

A associação da utilização do cimento de ionômero de vidro com a resina composta, empregado como um sobreforro, contribui para melhorar a performance do selamento cavitário na medida em que ao diminuir a espessura da resina na restauração reduz um dos aspectos negativos da contração de polimerização inerente à resina, ou seja, a infiltração e suas consequências negativas acima discutidas. A adesão química do ionômero permite uma interface adesiva mais coesa com o dente pois ele não contrai durante a fase de presa, além do mais, o coeficiente de expansão térmica linear e muito semelhante ao do dente, possibilita uma elevada estabilidade dimensional frente às oscilações térmicas que acontecem na cavidade bucal. Em contrapartida, a restauração concluída com a resina sobre a base de ionômero, contribui para uma maior resistência ao desgaste e à tração, bem como a obtenção de uma superfície mais lisa na restauração, além de ser levado em consideração a boa qualidade estética e maior durabilidade da resina (MEYER-LUECKEL $\mathrm{H}$, et al., 2016).

Kaya MS, et al. (2018) consideraram através de estudos estabelecidos que nas cavidades onde se prevalece as condutas conservadoras tanto na face oclusal quanto na ocluso-proximal, o cimento ionômero de vidro modificado por resina possui propriedades mecânicas melhores para serem indicados como um material para restaurações definitivas, já que possui maior firmeza quando comparado com o cimento de ionômero de vidro convencional.

\section{Cárie Dentária}

A doença cárie denota-se como um processo de natureza invasiva e devastadora que, se não cuidada, pode culminar com a perda do elemento dental, trazendo como consequências diretas na cavidade oral, problemas oclusais com a perda do equilíbrio necessário ao processamento alimentar e a instalação de disfunções temporomandibulares, como também na saúde do paciente como um todo e em especial nos portadores de doenças sistêmicas, tornando-se assim, um problema correlacionada a saúde pública na sociedade (BUSATO ALS e MALTZ M, 2014).

De acordo com França S (2016) a cárie não ocorre de uma única maneira e de forma rápida, ela é uma patologia multifatorial que vem passando por transformações ao longo do tempo na cavidade bucal do paciente, de modo que quanto mais cedo for tratada melhor. Um dos fatores que fazem com que ocorra a instalação da doença e seus avanços rápidos está relacionado à dieta dos indivíduos e a desregulamentação da microbiota oral, culminando com a diminuição do pH normal da boca. Posto isso, o estabelecimento da cárie é consequente de alterações resultantes de uma sequência de reações bioquímicas interconectadas, desencadeadas pelo aumento da acidez, decorrente do metabolismo das bactérias, uma dieta cariogênica descontrolada e distúrbios no processo de secreção de saliva entre outras causas. 
Esses acontecimentos desencadeiam um mal funcionamento do processo fisiológico responsável pela manutenção da integridade dos tecidos duros do dente, conhecido como desmineralização/remineralização, quando o índice de desmineralização supera a capacidade de remineralização, resultando na perda dos minerais presentes nos dentes e iniciando, por conseguinte, a cavitação na superfície dos dentes, que são na verdade sequelas deixadas pela doença (FELDENS CA e KRAMER PF, 2013).

No que concerne à cárie dental, particularmente quando é salientado o acúmulo de biofilme sobre as superfícies dentárias e a ingestão frequente de carboidratos ricos em macronutriente fermentados, com destaque no açúcar presente neles, é de se imaginar que o controle dela é perfeitamente possível e se restringe, basicamente, ao gerenciamento dos fatores desencadeadores supracitados aliados a um bom funcionamento do fluxo salivar (FELDENS CA e KRAMER PF, 2013).

Em concordância, Mota L, et al. (2013), respaldados por evidências científicas presentes na literatura, mostram que a sequência de eventos responsáveis por essa patologia, são capazes de serem comedidos por intervenções não invasivas. Para tanto, é importante se obter um equilíbrio entre os fatores desencadeantes da doença por modificações de práticas habituais de higiene bucal, modificações na dieta, utilização de fluoretos, e até de agentes antissépticos e antibióticos foram reportados como sendo eficazes, em distintos pontos de confirmações. A conduta terapêutica a ser seguida necessita ser estabelecida dentro de um planejamento no qual o diagnóstico correto da referida patologia e as dimensões da lesão são o ponto de partida na decisão de qual terapia seguir. Neste seguimento as condutas estabelecidas para o selamento de tecido cariado vêm ganhando destaque como sendo capaz de controlar as lesões, evitando perda desnecessária dos tecidos dentários que geralmente acontece enquanto ocorre o processo restaurador convencional.

Para Valentim VCB, et al. (2017) nos processos cariosos que apresentam grande profundidade e consequente proximidade com a polpa, é indispensável a submissão a uma conduta clínica capaz de interromper a sequência de eventos responsáveis pela progressão da doença, buscando assim inativar o processo carioso e permitindo uma reação do complexo dentina/polpa, na forma de criar uma barreira física que impedirá a doença de atingir a polpa. Porém, na grande maioria das vezes os profissionais optam por uma interferência operatória drástica visando a remoção de todo o tecido doente, no entanto essas condutas vêm ocasionando incertezas devido ao grande risco de exposição pulpar no decorrer da retirada da dentina danificada pela cárie. Baseando-se nos conceitos da OMI, a remoção seletiva da cárie e o selamento de tecido infectado na cavidade, vem ganhando cada vez mais adeptos já que é uma forma de interferência menos invasiva e, portanto, mais segura, capaz de evitar a perda prematura do dente.

\section{Lesão de cárie em dentina}

As lesões cariosas que envolvem a dentina têm início quando alcançam a junção amelodentinária que é formada pela mineralização da membrana basal em desintegração. Nesta ocasião, a parte mais externa da dentina passa por um processo de desmineralização que tem início até mesmo antes da respectiva lesão alcançar a dentina, isso ocorre porque, o complexo dentino-pulpar, na busca de diminuir ou até mesmo reprimir a entrada de bactérias, inicia assim a deposição de minerais dentro dos túbulos dentinários (IMPARATO JCP, et al., 2010).

Quando o corpo da dentinária é finalmente alcançada pela lesão, acontecerá a entrada indesejável de bactérias nos túbulos, com isso ela será aceleradamente decomposta por causa da ação de ácidos e enzimas proteolíticas que quebram ligações peptídicas entre os aminoácidos das proteínas, provenientes da fermentação dos carboidratos promovida pelos microrganismos (GUEDES-PINTO AC, 2012).

Caso não haja interrupção do processo carioso, a quantidade de microrganismos na cavidade só tende a aumentar juntamente com a produção de mais ácido. Na tentativa de se proteger, a polpa busca criar bloqueios com o objetivo de minimizar a invasão bacteriana e controlar a doença, para tanto, os odontoblastos que estão presentes no tecido pulpar secretam outra camada de dentina reacional, posicionada dessa vez na câmara pulpar sobre a polpa. Esta dentina, denominada dentina terciária, formada em resposta a fatores externos, também é reconhecida como dentina de origem patológica, pois forma-se a partir de estímulos nocivos como traumas e ação de ácidos produzidos por bactérias com o intuito de isolar a polpa (IMPARATO JCP, et al., 2010). 
Sendo assim, a dentina compreendida no local carioso está disposta em camadas ou zonas sobrepostas, com aspectos diferenciados em relação a quantidade de bactérias, minerais e tecido dentinário remanescente presentes no local bem como a capacidade de reestruturação da mesma. Clinicamente essas duas camadas da dentina cariada, distintas tanto no quesito morfológico e bioquímico, como também bacteriológico, podem ser identificadas tendo como parâmetro a dureza e a coloração que elas apresentam, desse modo, a dentina superficial é mais clara, bastante desestruturada (amolecida) e mais infectada, enquanto que a camada adjacente e mais profunda, apresenta-se mais escura, endurecida e menos infectada (IMPARATO JCP, et al., 2010; FRENCKEN JE, et al., 2012).

Com o intuito de aprofundar o conhecimento sobre o assunto, Valentim VCB, et al. (2017) avaliaram os achados de estudos já publicados nessa área em busca de comprovações que respaldassem a implementação de um processo terapêutico seguro e minimamente invasivo que fosse eficiente e que assegurasse a vitalidade pulpar em elementos dentais permanentes. Os autores analisaram três técnicas de tratamento sugeridas nos estudos, o procedimento mais empregado e menos conservador propunha a retirada completa das camadas de dentina atingidas pela cárie até alcançar um tecido endurecido considerado sadio e livre de bactérias independente do risco de exposição pulpar.

A segunda conduta avaliada, prescrevia a remoção total da dentina amolecida, deixando intacta a camada afetada pela ação ácida, seguido do selamento provisório da cavidade com cimento de ionômero de vidro; esta técnica recebeu o nome de tratamento expectante porque, após um tempo de espera a cavidade era novamente aberta, todo o tecido afetado era removido e a cavidade restaurada definitivamente. $E$ finalmente a terceira técnica, mais flexível, preconizava a remoção seletiva da dentina amolecida, deixada permanentemente sobre a polpa. Ao final da revisão integrativa e respaldados nos resultados encontrados, os autores concluíram que tanto o tratamento expectante quanto a remoção seletiva da cárie são formas de intervenção mais seguras e eficazes ao passo que a remoção total da cárie foi considerada um procedimento muito invasivo com elevado grau de exposição pulpar (VALENTIM VCB, et al., 2017)

Segundo Frencken JE, et al. (2012) o tratamento convencional seguindo os critérios clínicos de resistência e dureza, como parâmetro para guiar a remoção completa da cárie, não é indicativo de que a área considerada sadia esteja livre de microrganismo correlacionados ao processo carioso. Estudos realizados com o objetivo de aferir a carga microbiana remanescente em cavidades seladas após a remoção seletiva da dentina cariada, mostraram que, com o tempo, o selamento da dentina cariada resulta em níveis mais baixos de infecção, reduzindo a viabilidade bacteriana e interrompendo a progressão da lesão, não havendo, portanto, a necessidade de remover toda a dentina cariada antes da restauração definitiva (MALTZ M et al., 2012; CONTARDO MS et al., 2015; BITELLO-FIRMINO L et al., 2018).

Trabalhos bem conduzidos demonstram benefícios dos tratamentos menos invasivos em que a retirada parcial da cárie de dentina de dentes permanentes é preconizada, principalmente nos tratamentos em que há risco de exposição pulpar (BUSATO ALS e MALTZ M, 2014). Essa manobra, além de diminuir os riscos de exposição, possibilita uma reação de defesa desse tecido, aumentando as chances de manutenção da vitalidade pulpar (KLEINA MW, et al., 2009). Vale salientar que, mesmo aderindo a uma metodologia minimamente invasiva mantendo dentina amolecida na cavidade, nas circundantes devem der instrumentadas de forma a remover completamente a dentina cariada, caso contrário, a adesão material restaurador ficará comprometida (GIANINI RJ, et al., 2010).

\section{Dentina Infectada}

A dentina infectada é principalmente amolecida, dispondo de uma cor amarela clara, com uma aparência úmida. Histologicamente, a dentina apresenta-se desmineralizada, com um processo de degradação das fibrilas colágenas as quais são responsáveis pela força e resistência a tração e flexibilidade aos tecidos, além de estarem muito contaminadas, em vista disso, a dentina infectada não é suscetível ao processo de reorganização histológica, e remineralização, tendo que ser retirada por completo durante o preparo da cavidade (ZUCCHELLI G, et al., 2013).

\section{Dentina Afetada}

Enquanto a dentina infectada localiza-se na parte mais externa a dentina afetada está na porção mais interna, possuindo como peculiaridades baixo nível de desmineralização com conservação da malha colágena 
e área menos contaminada no que se refere às bactérias presentes, dispondo de viabilidade de ocorrer a remineralização. Devido ao baixo índice de desmineralização, se mostra mais endurecida ao toque, quando comparada à dentina infectada, quando passa pelo processo de curetagem, solta-se com formatos de lascas, na maioria das vezes possui pigmentação com tonalidade amarela escura quase acastanhada (GUEDESPINTO AC, 2012). A manutenção desta camada mais interna da dentina atingida pela cárie, diminui significativamente a chance de ocorrer um resultado indesejado futuramente, como exposição e/ou necrose da polpa, os quais poderão levar a um indesejado tratamento endodôntico (IMPARATO JCP, et al., 2010; FEJERSKOV O e KIDD E, 2011).

\section{CONSIDERAÇÕES FINAIS}

A Odontologia Minimamente Invasiva tem demostrado efetividade nos tratamentos estabelecidos, deixando claro que o melhoramento dos materiais restauradores adesivos, e consequentemente do selamento da cavidade, é de suma relevância para o sucesso desta técnica inovadora. A retirada por completo da cárie, em elementos dentais que apresentam cavidades mais profundas, foi apontada como sendo uma técnica invasiva e dispensável evitando uma possível exposição da polpa. A OMI vem demostrando boa aplicabilidade no tocante à remoção seletiva da cárie, todavia é complexo substituir dogmas que foram seguidos há anos pelos profissionais da área odontológica.

\section{REFERÊNCIAS}

1. BITELLO-FIRMINO L, et al. Microbial Load After Selective and Complete Caries Removal in Permanent Molars: a Randomized Clinical Trial. Braz Dent J. 2018; 29(3):290-295.

2. BUSATO ALS, MALTZ M. Cariologia: Aspectos de dentística restauradora. São Paulo: Artes Médicas, $2014 ; 125$.

3. CONTARDO MS, et al. Sealing Dentin Caries with Resin-Modified Glass Ionomer Decreases Lesion Progression and Bacterial Survival in an Experimental Model. J Adhes Dent. 2015;17(3):207-12.

4. EL-SAFTY S, et al. Nanomechanical properties of dental resincomposites. Dent Mater 2012; 28:1292-1300

5. FEJERSKOV O, KIDD E. Cárie Dentária: a doença e seu tratamento clínico. 2ª.ed. São Paulo:Santos; 2011.

6. FEJERSKOV O. et al. Cárie Dentária: fisiopatologia e tratamento. 3. ed. Rio de Janeiro: Guanabara Koogan. 2017;7: 291.

7. FELDENS CA, KRAMER PF. Cárie Dentária na Infância: uma abordagem contemporânea. São Paulo: Santos, 2013; 295.

8. FRANÇA S. Odontologia restauradora na era adesiva. Revista Associação Paulista de Cirurgiões- Dentistas, São Paulo. 2016; 70, (3): 234-241.

9. FRENCKEN JE, et al. Minimal Intervention Dentistry for managing dental caries - a review: report of a FDI task group. Int Dent J. 2012; 62(5): 223-43.

10. GIANINI RJ, et al. Microtensile Bond strength of eych-and-rinse and self-etch adhesive systems to demineralized dentin after use of a papain-based chemomechanical method. Am J Dent 2010; 23(1):23-8.

11. GUEDES-PINTO AC. Odontopediatria. 8. ed. São Paulo: Santos, 2012; 1048.

12. IMPARATO JCP, et al. SELAMENTO DE CÁRIE: Uma Alternativa para Tratamento de Lesões de Cárie em Dentina. São Paulo: Santos, 2010.

13. KAYA MS, et al. Structural and mechanical properties of a giomer-based bulk fill restorative in different curing conditions. J Appl Oral Sci, Turkey, 2018.

14. KLEINA MW, et al. A remoção da dentina cariada na prática restauradora-Revisão de literatura. Dentística on-line, Cachoeira do Sul, 2009; 8, (18): 15-23.

15. MALTZ M, et al. Conventional caries removal and sealed caries in permanent teeth: a microbiological evaluation. $J$ Dent. 2012;40,(9):776-82.

16. MASSARA MLA, et al. Tratamento Restaurador Atraumático Modificado (ARTm). Pesquisa Brasileira de Odontopediatria e Clinica Integrada. Revista UEPB. João Pessoa. 2012; 12, (3):303-306.

17. MEYER-LUECKEL H, et al. Cariologia: Ciência e prática clínica. Rio de Janeiro: Elsevier. 2016; 3, (2):303.

18. MOTA L, et al. Dentística Minimamente Invasiva Através da Remoção Parcial de Dentina Cariada em Cavidades Profundas. Cientistas, Ciência, Biologia e Saúde. João Pessoa: 2013;15, (2): 145-152.

19. RUNGCHARASSAENG K, et al. Immediate Implant Placement and Provisionalization With and Without Connective Tissue Graft: An Analysis of Facial Gingival Tissue Thickness. Int J Periodontics Restorative Dent 2012; 32: 657-663.

20. SANTOS ML. Complicações Endodônticas: Discussão dos tratamentos endodônticos e seus possíveis acidentes: perfurações, degraus e fraturas. 27 folhas. Trabalho de Conclusão de Curso de Odontologia - Faculdade de Macapá/FAMA. Macapá, 2017.

21. VALENTIM VCB, et al. Tratamento de lesões de cárie profunda com risco de exposição pulpar - decisão baseada em evidências. Rev. Odontol. Univ. Cid., São Paulo. 2017; 29,(2); 163-173.

22. WALSH LJ, BROSTEK AM. Minimum intervention dentistry principles and objectives. Australian Dental Journal, Austrália, 2013; 58: 3-16.

23. ZUCCHELLI G, et al. Esthetic Surgical_prosthetic Approach. Int J Periodontics Restorative Dent 2013; 33: 327-335. 